AperTO - Archivio Istituzionale Open Access dell'Università di Torino

\title{
A new practical synthesis of triaryl and trisindolylmethanes under solvent-free reaction conditions
}

\section{This is the author's manuscript}

Original Citation:

Availability:

This version is available http://hdl.handle.net/2318/90947

since

Published version:

DOI:10.1039/C1OB06280H

Terms of use:

Open Access

Anyone can freely access the full text of works made available as "Open Access". Works made available under a Creative Commons license can be used according to the terms and conditions of said license. Use of all other works requires consent of the right holder (author or publisher) if not exempted from copyright protection by the applicable law. 


\section{(6) \\ UNIVERSITÀ DEGLI STUDI DI TORINO}

This is an author version of the contribution published on:

Questa è la versione dell'autore dell'opera:

[Org. Biomol. Chem., 9 (24), 2011, 8393-8399, DOl: 10.1039/c1ob06280h]

The definitive version is available at:

La versione definitiva è disponibile alla URL:

[http://pubs.rsc.org/en/journals/journalissues/ob\#!recentarticles\&all] 


\title{
A new practical synthesis of triaryl and trisindolylmethanes under solvent-free reaction conditions
}

\author{
Margherita Barbero,* Silvano Cadamuro, Stefano Dughera, Claudio Magistris and Paolo Venturello
}

An efficient and practical synthesis of triaryl and trisindolylmethanes is reported via the bisarylation of aryl aldehydes with activated arenes. The new method features mild solvent-free reaction conditions, in most cases nearly stoichiometric reagent ratios, catalytic amount of the readily available, easily-handled, recoverable and reusable Brønsted acid catalyst $o$-benzenedisulfonimide.

\section{Introduction}

Triaryl and triheteroarylmethanes (TRAMs) are valuable scaffolds which have attracted attention from the scientific community not only for their interesting chemical properties, but also for the widespread applications they have found in many fields, ${ }^{1}$ such as useful protective groups, ${ }^{2}$ photocromic agents, ${ }^{3}$ dyes, ${ }^{4}$ and building blocks for dendrimers and NLOs. ${ }^{5}$ Ring hydroxylated TRAMs exhibit antioxidant, antitumor, antitubercolar, antivirus, antifungal and anti-inflammatory activities. ${ }^{6}$ Triarylmethane frameworks are usually obtained from the acid-catalysed bisarylation of activated aryl aldehydes and the reaction is called hydroxyalkylation. It is in fact a multistep Friedel-Crafts alkylation and follows a typical aromatic electrophilic substitution mechanism. The reaction does not stop at the first step, and the intermediate diarylmethanol immediately reacts with a second molecule of the aromatic compound, giving rise to a bisarylation product. Furthermore the reaction benefits from a high atom efficiency and only produces one molecule of water as a by-product.

The reaction has been extensively studied since $1886^{7}$ and literature methods include superacidic systems, Brønsted and Lewis acid catalysts and solid-supported catalysts. $\mathrm{AuCl}_{3},{ }^{8} \mathrm{Yb}(\mathrm{OTf})_{3},{ }^{9} \mathrm{ClSiMe}_{3},{ }^{10} \mathrm{~B}\left(\mathrm{C}_{6} \mathrm{~F}_{5}\right)_{3}{ }^{11}$ and molecular iodine ${ }^{12}$ have been used as Lewis acids in catalytic amounts. A dual-reagent catalytic combination of $\left[\operatorname{Ir}(\mathrm{COD}) \mathrm{Cl}_{2}-\mathrm{SnCl}_{4}\right.$ has also been reported to catalyse the Friedel-Crafts alkylation of arenes and heteroarenes; a complexation/interaction of the carbonyl functionality at the tin center has been suggested as a plausible mechanism. ${ }^{13}$

Mineral Brønsted acids (such as $\mathrm{HF}, \mathrm{H}_{2} \mathrm{SO}_{4}, \mathrm{H}_{3} \mathrm{PO}_{4}$ ) have been predominantly used as the catalysts for a very long time. The detailed mechanism of the reaction was investigated in-depth by Olah and coworkers, by running the reaction in various superacidic systems (triflic acid, Magic acid, and so on). Experimental evidence and theoretical calculations suggested the possible formation of superelectrophilic $O, C$-diprotonated aldehydes. ${ }^{14}$ Recently, Olah and coworkers reported the hydroxyalkylation of activated or weakly deactivated aromatics by aromatic mono- and dicarbaldehydes in the presence of $\mathrm{BF}_{3}-\mathrm{H}_{2} \mathrm{O}$ (1:1 complex; 50 equiv.; in a pressure tube and under closed conditions). ${ }^{15}$ This stable complex has been used in a dual role, as a suitable protic solvent/protosolvating medium and as a strong Brønsted acid catalyst.

An excess of TfOH under pressure, ${ }^{16}$ TFA and other protic acids, ${ }^{6,17}$ PTSA $^{18}$ and $84 \%$ sulfuric acid ${ }^{19}$ have also been used. Heterogeneous solid Brønsted acid catalysts include silica gel-supported $\mathrm{NaHSO}_{4},{ }^{20}$ polystyrene-supported sulfonic acid, ${ }^{21}$ silica sulfuric acid, ${ }^{22}$ perfluorinated sulfonic acid resin (Nafion-H). ${ }^{23}$ Unsymmetrical TRAMs have been prepared using $\mathrm{ZnBr}_{2} / \mathrm{SiO}_{2}$ and $\mathrm{AcBr},{ }^{24}$ whilst symmetrical and unsymmetrical TRAMs using $\mathrm{FeCl}_{3} / \mathrm{Ac}_{2} \mathrm{O}$ : ${ }^{25}$ the reaction mechanisms involves the in situ formation of an $\alpha$-bromobenzyl acetate or a geminal diacetate, respectively, as the reactive intermediate species.

All the above TRAMs synthetic methods, however, suffer from one or more known disadvantages, such as the need for a large excess of the aromatic substrate, poor selectivity, harsh reaction conditions (e.g. high temperatures, pressure vessels), large catalyst amounts and the disposal of the excess aromatic compound or solvents and/or toxic metal waste.

Finally, bis- and trisindolylmethanes (usually 3,3'-BIMs and 3,3',3'-TIMs) have proven themselves to be of great interest thanks to their wide range of applications. The numerous synthetic strategies towards their preparation, powerful biological activity and different properties have recently been extensively reviewed. ${ }^{26}$ The standard acid-catalysed indole reaction with carbonyl compounds is a useful synthetic method and a huge number of Lewis or Brønsted acid catalysts has been reported. Similarly, the reactions of substituted indoles with 3-formylindole give asymmetric TIMs. ${ }^{26}$ In the same review a catalyst-free BIM formation was reported to occur in glycerol at $90{ }^{\circ} \mathrm{C} .^{27}$

Despite the high number of literature methods, the demand for new efficient, mild, metal-free and environmentally friendly protocols for TRAM, BIM and TIM synthesis, via electrophilic substitution reaction, is high. In order to continue our ongoing studies in the field of organocatalysis, ${ }^{28 a}$ which are aimed at developing mild and practical protocols in neat conditions, we have decided to explore the synthetic features of the use of $o$-benzenedisulfonimide (OBS, 1) ${ }^{28 \mathrm{~b}}$ as an environmentally friendly Brønsted acid catalyst in Friedel-Crafts hydroxyalkylation reactions (Scheme 1 and Table 1). Furthermore, a new bench-stable solid-supported catalyst, namely silica-gel supported OBS, has been prepared and tested to improve the easy handling, storing, recovery and recycling of this catalyst under clean and easy work-up conditions. ${ }^{29}$ 


$$
\begin{aligned}
& \overbrace{1}^{\mathrm{SO}_{2}^{\prime} \mathrm{O}_{2}} \mathrm{SO}_{2} \\
& \mathrm{ArCHO}\left(\text { or } \mathrm{ArCH}(\mathrm{OMe})_{2}\right)+\mathrm{Ar}^{\prime} \mathrm{H} \longrightarrow \mathrm{ArCHAr}_{2} \\
& \text { 2a-f 3a-b 4a-j 5-11 }
\end{aligned}
$$

Scheme 1 Triaryl and trisindolylmethane synthesis via OBS catalysed bisarylation of aryl aldehydes (or their dimethyl acetals)

Table 1 Reagents $2 \mathbf{a}-\mathbf{f}, 3 \mathbf{a}-\mathbf{b}$, and $4 \mathbf{a}-\mathbf{j}$

$\begin{array}{llllll}\mathbf{2} & \mathrm{Ar} & \mathbf{3} & \mathrm{Ar} & \mathbf{4} & \mathrm{Ar}{ }^{\prime} \mathrm{H} \\ \mathbf{2 a} & 4-\mathrm{NO}_{2} \mathrm{C}_{6} \mathrm{H}_{4} & \mathbf{3 a} & 4-\mathrm{NO}_{2} \mathrm{C}_{6} \mathrm{H}_{4} & \mathbf{4 a} & 1,2,4-(\mathrm{MeO})_{3} \mathrm{C}_{6} \mathrm{H}_{3} \\ \mathbf{2 b} & 4-\mathrm{ClC}_{6} \mathrm{H}_{4} & \mathbf{3 b} & 4-\mathrm{MeOC}_{6} \mathrm{H}_{4} & \mathbf{4 b} & 1,3-(\mathrm{MeO})_{2} \mathrm{C}_{6} \mathrm{H}_{4} \\ \mathbf{2 c} & \mathrm{C}_{6} \mathrm{H}_{5} & & & \mathbf{4 c} & 1,2-(\mathrm{MeO})_{2} \mathrm{C}_{6} \mathrm{H}_{4} \\ \mathbf{2 d} & 4-\mathrm{MeOC}_{6} \mathrm{H}_{4} & & & \mathbf{4 d} & \mathrm{C}_{6} \mathrm{H}_{5} \mathrm{OMe} \\ \mathbf{2 e} & 4-\mathrm{HOC}_{6} \mathrm{H}_{4} & & & \mathbf{4 e} & \mathrm{C}_{6} \mathrm{H}_{5} \mathrm{OH} \\ \mathbf{2 f} & 3-\mathrm{Indolyl} & & & \mathbf{4 f} & \text { Indole } \\ & & & & \mathbf{4 g} & 1-\text { Methylindole } \\ & & & \mathbf{4 h} & \text { 2-Methylfuran } \\ & & & \mathbf{4 i} & \text { Thiophene } \\ & & & \mathbf{4 j} & \text { 2-Methylindole }\end{array}$

\section{Results and discussion}

First, 4-nitrobenzaldehyde (2a) and anisole (4d) were reacted to give TRAM 5d, as a model reaction of the OBS catalysed Friedel-Crafts hydroxyalkylation. The reagents were chosen as the first is a highly electrophilic alkylating agent and the second a sufficiently activated aromatic substrate (Scheme 2). Following literature suggestions, anisole excess was reacted with $\mathbf{2 a}$ in the presence of $\mathbf{1}$, which was used as the catalyst, in neat conditions. The effect of reagent ratio, heating and catalyst loading were considered as reported in Table 2 . Both a temperature of $130{ }^{\circ} \mathrm{C}$ and the catalytic amount of 1 were crucial to the completion of the reaction in reduced times (entries 2 and 4 compared with 1 and 3; Table 2).

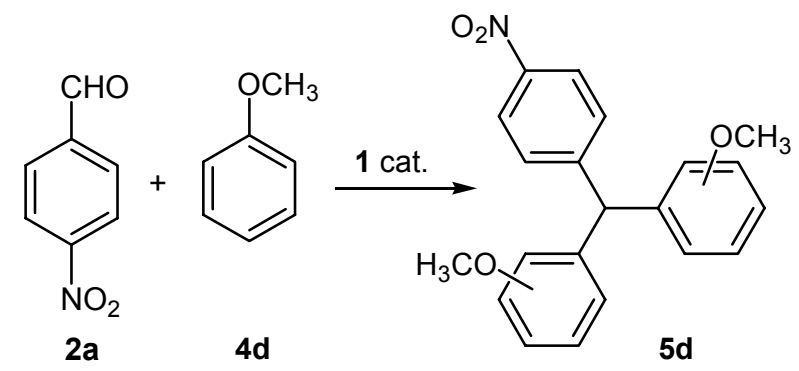

\begin{tabular}{|c|c|c|c|c|c|}
\hline Entry & Molar ratio $\mathbf{2 a}: \mathbf{4 d}$ & $1(\mathrm{~mol} \%)$ & $\mathrm{T}\left({ }^{\circ} \mathrm{C}\right)$ & $\mathrm{t}(\mathrm{h})$ & Yield $^{\mathrm{a}}(\%)$ \\
\hline 1 & $1: 10$ & 10 & 130 & 24 & $86(5.9: 1)$ \\
\hline 2 & $1: 10$ & 50 & 130 & 1.5 & $91(5.6: 1)$ \\
\hline 3 & $1: 2 \mathrm{~mL}$ & 10 & 130 & 24 & $89(6.9: 1)$ \\
\hline 4 & 1: $2 \mathrm{~mL}$ & 50 & 130 & 1.5 & $90(7.6: 1)$ \\
\hline 5 & $1: 2 \mathrm{~mL}$ & $50^{\mathrm{b}}$ & 130 & 1.5 & $100(5.2: 1)$ \\
\hline
\end{tabular}

Scheme 2 Model reaction between aldehyde $\mathbf{2 a}$ and anisole (4d)

Table 2 Reaction condition optimization for $\mathbf{5 d}$ synthesis

${ }^{a}$ Yields refer to pure isolated product by column chromatography (eluent PE:AcOEt 6:4). In parentheses $p, p$ and $o, p$ isomer ratio is reported (calculated by ${ }^{1} \mathrm{H}$ NMR spectra). ${ }^{\mathrm{b}}$ Silica-gel supported OBS $(10 \% \mathrm{w} / \mathrm{w})$.

Reaction temperature of $100{ }^{\circ} \mathrm{C}$ and room temperature only led to trace amount or a complete absence of product. In all the reactions, the formation of diarylated regioisomer products was observed, as the expected consequence of an electrophilic aromatic substitution pathway. The para,para derivative was always predominant with respect to the ortho,para isomer, whereas the ortho,ortho was never detected; a larger anisole excess increased the selectivity (entries 3 and 4 compared to 1 and 2). The reaction was then carried out in the presence of silica-gel supported OBS following the optimized conditions. The Brønsted acid was adsorbed onto $\mathrm{SiO}_{2}$ in a $10 \% \mathrm{w} / \mathrm{w}$ amount, simply by dissolving it in water, stirring with $\mathrm{SiO}_{2}$ and by evaporating the solvent under vacuum. Then its catalytic efficiency was tested and a quantitative product yield was 
recovered (entry 5).

Then, a representative number of variously substituted aromatic (and heteroaromatic) aldehydes $\mathbf{2 a - f}$ were reacted with activated aromatic and heteroaromatics $(\mathbf{4} \mathbf{a}-\mathbf{j}$; Table 1), in the presence of OBS (Scheme 1). In all the reactions, the catalytic amount of OBS was not lowered below $10 \%$ mol, although highly activated aryl aldehydes and aromatics could react in the presence of less catalyst. Details of the reaction conditions and isolated yields of products 5-11 (Table 3) are reported in Table 4.

The obtained results are strictly depending on the substituent electronic effects of the starting reagents towards electrophilic hydroxyalkylation.

First, the OBS-catalysed hydroxyalkylation of aromatics was tested using the highly electrophilic 4-nitrobenzaldehyde (2a). Reactions were initially performed at $130{ }^{\circ} \mathrm{C}$ in presence of an excess of the aromatic substrate, like the trial reactions (entries 1 and 8). Whereas anisole required these harsh conditions, it was observed that, using $\mathbf{2 a}$, room temperature, nearly stoichiometric amounts of reagents and neat conditions were sufficient to obtain, under stirring, the same good results in the reaction with highly activated aromatics $\mathbf{4 a}, \mathbf{4 b}$ and $\mathbf{4 e}$, and heteroaromatics $\mathbf{4 f}, \mathbf{4 g}$ and $\mathbf{4 h}$ (entries 2, 4, 9, 11, 13 and 15). The reaction was immediate and reached completion in very short times. In some cases, the deep coloured thick reaction mixture suddenly became solid while lost its colouring.

By using less activated $4 \mathbf{c}$ and $\mathbf{4 i}$, heating at $130{ }^{\circ} \mathrm{C}$ or at $4 \mathbf{i}$ reflux temperature was needed and a higher catalyst amount increased product yields (entries 6-7 and 17-18). As highlighted for anisole, regioisomers were produced when phenol was used (4e; entries 8 and 9). The yields of column chromatography purified products $\mathbf{5 a}-\mathbf{h}$ were always good to high, only $\mathbf{5 i}$ was isolated in modest yield (entry 18). Unfortunately, the OBS-catalysed hydroxyalkylation of deactivated substrates such as benzene, $p$-xylene or chlorobenzene was not achieved.

Some of the above reactions were then run in the presence of OBS adsorbed onto silica $10 \% \mathrm{w} / \mathrm{w}$. The catalytic activity of this heterogeneous system was comparable to OBS alone (entries 3,5,10,12,14 and 16), whilst the recovery and recyclability of the catalyst were improved. Indeed, at the end of the reaction, after the extraction of the organic phase and a few washings with small amounts of solvent, the solid catalyst was dried and immediately recycled in another five subsequent reactions without significant loss of catalytic activity (entry 14).

Then, 4-chlorobenzaldehyde (2b) was reacted, under the same conditions as $\mathbf{2 a}$, with the aromatic compounds $\mathbf{4 a}, \mathbf{4 e}$ and 4g (entries 19-21). Despite the weaker electron withdrawing effect of the chloro substituent, the desired TRAMs were obtained in good to quantitative yields both in the presence of OBS or silica-supported OBS. TRAM $\mathbf{6 b}$ has been reported as an antiviral. ${ }^{30}$ Benzaldehyde (2c) was similarly reacted with aromatics $\mathbf{4 a}$ and $\mathbf{4 f}$ (entries $22-24$ ). The results were good, but heating was necessary in the first case to reduce reaction time. Less activated 4-methoxybenzaldehyde (2d) was reacted with $\mathbf{4 a}, \mathbf{4 e}$ and $\mathbf{4 f}$. Heating was required to obtain TRAMs 8a and $\mathbf{8 b}$ in good yields (entries 25-26), whereas $\mathbf{8 c}$ was obtained in milder conditions (entry 27). Finally, the antimicrobial ${ }^{31}$ TRAM 9a was prepared from 4-hydroxybenzaldehyde (2e) and $4 \mathbf{f}$ at $40{ }^{\circ} \mathrm{C}$ in order to favour the mixing of the reagents.

Aldehyde acetals are well-known highly electrophilic aldehyde substitutes. ${ }^{28 a}$ Therefore, acetals $\mathbf{3 a}$ and $\mathbf{3 b}$ were tested in order to evaluate their applicability in hydroxyalkylation reactions. Obtained results were as expected (Scheme 1, Table 4). The reactions of 4-methoxybenzaldehyde dimethyl acetal $(\mathbf{3 b})$ with $\mathbf{4 a}$ and with $\mathbf{4 e}$ at room temperature were instantaneous (entries 29 and 30), whilst the reaction of the aldehyde $\mathbf{2 d}$ with $\mathbf{4 a}$ did not

complete at room temperature and when stopped after 24 hours only gave rise to $\mathbf{8 a}$ in a $50 \%$ yield. Unfortunately, with deactivated aromatics such as $\mathbf{4 i}$, acetal hydrolysis was the only observed reaction. 4-Nitrobenzaldehyde dimethyl acetal (3a), however, did not prove to be a useful alternative to the parent aldehyde 2a (entry 31 compared to entry 4). Furthermore, the hydrolysis was the only observed process in the reaction with $\mathbf{4 i}$. The difference in acetal behaviour is probably due to the different electronic effects the methoxy and the nitro groups have on the acetal protonation in the first step of the reaction, giving rise to an inversion in the parent aldehyde reactivity order. The use of acetals can therefore be useful in the case of aldehydes bearing electron-donating substituents which induce lower reactivity in the Friedel-Crafts hydroxyalkylation.

When we performed the reaction with aldehydes, immediate colour and density changes in the reaction mixtures were observed which led us to investigate the reaction further. The reactions with indoles, in particular, were seen to produce a thick, deep orange coloured mixture simply by mixing the reagents. Therefore we decided to carry out some reactions starting from particularly activated reagents, in the absence of any catalyst, in neat conditions. To the best of our knowledge, Friedel-Crafts hydroxyalkylation reactions without catalyst are here reported for the first time (in the paper cited above, the reactions were run in glycerol under heating and the role of the protic solvent in promoting aldehyde activation, through hydrogen bonding, was considered a plausible explanation). ${ }^{27}$

TRAMs $\mathbf{5 f}, \mathbf{g}, \mathbf{j}$ were obtained in good yields and in short times from aldehyde $\mathbf{2 a}$ and indoles $\mathbf{4 f}, \mathbf{4} \mathbf{g}$ and $\mathbf{4 j}$ when the reagents were heated in stoichiometric amounts at $100{ }^{\circ} \mathrm{C}$ (at r.t. the reaction did not reach completion). However the deep red coloured reaction mixture of $\mathbf{2 a}$ and $4 \mathbf{4}$ did not give products, even after several hours of heating at $130{ }^{\circ} \mathrm{C}$. The reactions between the less activated aldehyde $\mathbf{2 d}$ and $\mathbf{4 f}$ or $\mathbf{4 g}$ proceeded, but did not complete in comparable times.

Turning our attention to indolylmethanes, as a general mechanism pathway, the first step of the acid-catalysed indole reaction with carbonyl compounds produces, by dehydration, an intermediate azafulvenium species (10), which then 
immediately undergoes the addition of a second indole moiety to produce the expected BIM (Scheme 3 ). ${ }^{26}$

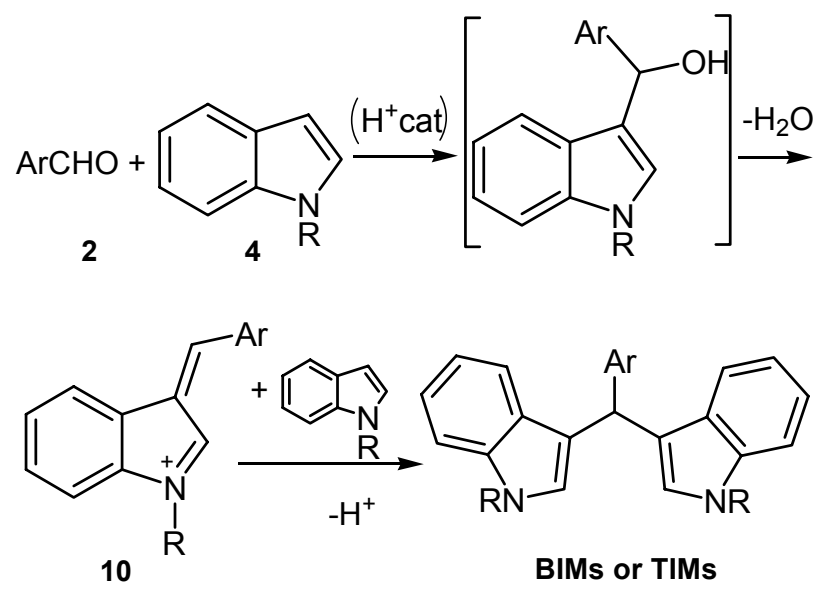

Scheme 3 Reaction mechanism

The reaction between 3-formylindoles and indoles produce TIMs with the same mechanism (Scheme 3; Ar = 3-indolyl). It is also known that trisindolylmethanes are readily cleaved by acids giving rise to resonance stabilised ammonium ions. ${ }^{23}$ Furthermore, symmetric and asymmetric TIMs have been isolated as a mixture from the reaction of 3-formylindoles with substituted indoles in the presence of different acid catalysts. ${ }^{32}$ Their formation, although not always justified, has been attributed to the likely acidic cleavage of the initially formed TIMs with release of an indole molecule and subsequent reaction with a substituted indole moiety. Interested in these findings, we decided to further explore the applicability of OBS as the catalyst in trisindolylmethane synthesis.

First of all, we tested the optimised reaction conditions for TRAM synthesis, but the reaction between $\mathbf{2 f}$ and indole (4f) in the presence of $1(10 \mathrm{~mol} \%)$ in solid state conditions did not proceed at r.t. When heating to 55 or $100{ }^{\circ} \mathrm{C}$, the reaction seemed to be locked in an unchanging ratio between reagents and products. Nevertheless, in ethanol as a solvent, the reaction at r.t. was instantaneous and the good yield (Table 5, entry 1). A control experiment carried out in EtOH in the absence of the catalyst did not yield traces of product. Good results were also obtained by reacting 2 f and 2-methylindole (4j) at r.t. in the presence of OBS $10 \%$ (entry 2).

According to literature observations, we suggest that, in these conditions, the lowest solubility of TIMs in ethanol causes their immediate separation from the reaction medium so preventing the acid-catalysed cleavage. In the light of these, we can hypothesize that, under the former acidic neat conditions and heating, the produced TIM is rapidly cleaved into the intermediate cation and the reaction cannot reach completion. Furthermore, when $\mathbf{2} \mathbf{f}$ and 1-methylindole (4g) were reacted under the same reaction conditions, the immediate formation of two products was observed: the expected TIM 11c and the symmetric TIM 11d deriving by cleavage of the former and reaction with excess $\mathbf{4 g}$ (Scheme 4). The reaction was heated to $50{ }^{\circ} \mathrm{C}$ in order to maximize 11d formation and stopped after $24 \mathrm{~h}$. Products were identified by comparison with authentic samples or by NMR spectroscopy of isolated products. GC and GC-MS analyses confirmed indole (4f) formation in the reaction mixture, whose presence is not otherwise explainable. Nevertheless, TIM 11c was obtained in $90 \%$ yield by carrying out the reaction in the presence of OBS $2 \mathrm{~mol} \%$ (only traces of 11d were observed in these conditions; entry 3 ). 
Table 3 Products 5a-j, 6a-c, 7a-b, 8a-c, 9a, 11a-d.<smiles>[R]c1ccc(C(c2cc(OC)c(OC)cc2OC)c2cc(OC)c(OC)cc2OC)cc1</smiles>

6a: $\mathrm{R}=\mathrm{Cl}$

7a: $\mathrm{R}=\mathrm{H}$

8a: $\mathrm{R}=\mathrm{MeO}$<smiles>[R]c1ccc(C(c2c[nH]c3ccccc23)c2c[nH]c3ccccc23)cc1</smiles>

5f: $\mathrm{R}=\mathrm{NO}_{2}$

7b: $\mathrm{R}=\mathrm{H}$

8c: $\mathrm{R}=\mathrm{MeO}$

9a: $\mathrm{R}=\mathrm{HO}$<smiles>[R]c1c(OC)ccc(C(c2ccc([N+](=O)[O-])cc2)c2ccc(OC)c([R])c2[R])c1[R]</smiles>

5b: $\mathrm{R}^{1}=\mathrm{H} ; \mathrm{R}^{2}=\mathrm{MeO}$

5c: $\mathrm{R}^{1}=\mathrm{MeO} ; \mathrm{R}^{2}=\mathrm{H}$

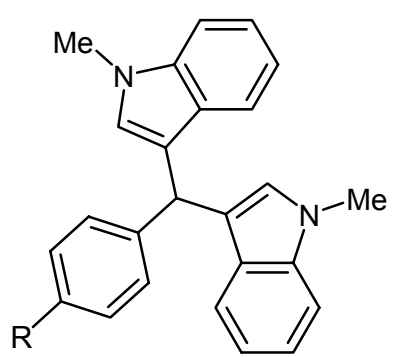

5g: $\mathrm{R}=\mathrm{NO}_{2}$

6c: $\mathrm{R}=\mathrm{Cl}$<smiles>COc1ccccc1C(c1ccc([N+](=O)[O-])cc1)c1ccccc1OC</smiles><smiles>[R]c1ccc(C(c2ccccc2)c2cccc(O)c2)cc1</smiles>

5e: $\mathrm{R}=\mathrm{NO}_{2}$

6b: $\mathrm{R}=\mathrm{Cl}$

8b: $\mathrm{R}=\mathrm{MeO}$

5i: Ar= 2-thienyl

5j: Ar= 2-Me-3-indolyl

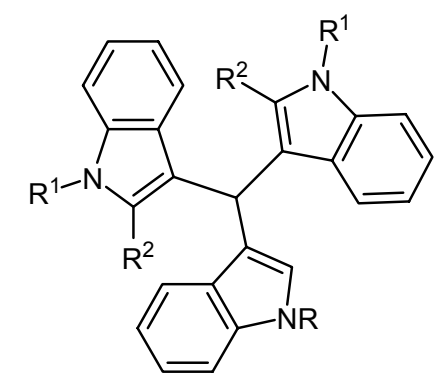

11a: $R=R^{1}=R^{2}=H$

11b: $R=R^{1}=H ; R^{2}=M e$

11c: $R^{1}=M e ; R=R^{2}=H$

11d: $R=R^{1}=M e ; R^{2}=H$ 
Table 4 Synthesis of products 5-9.

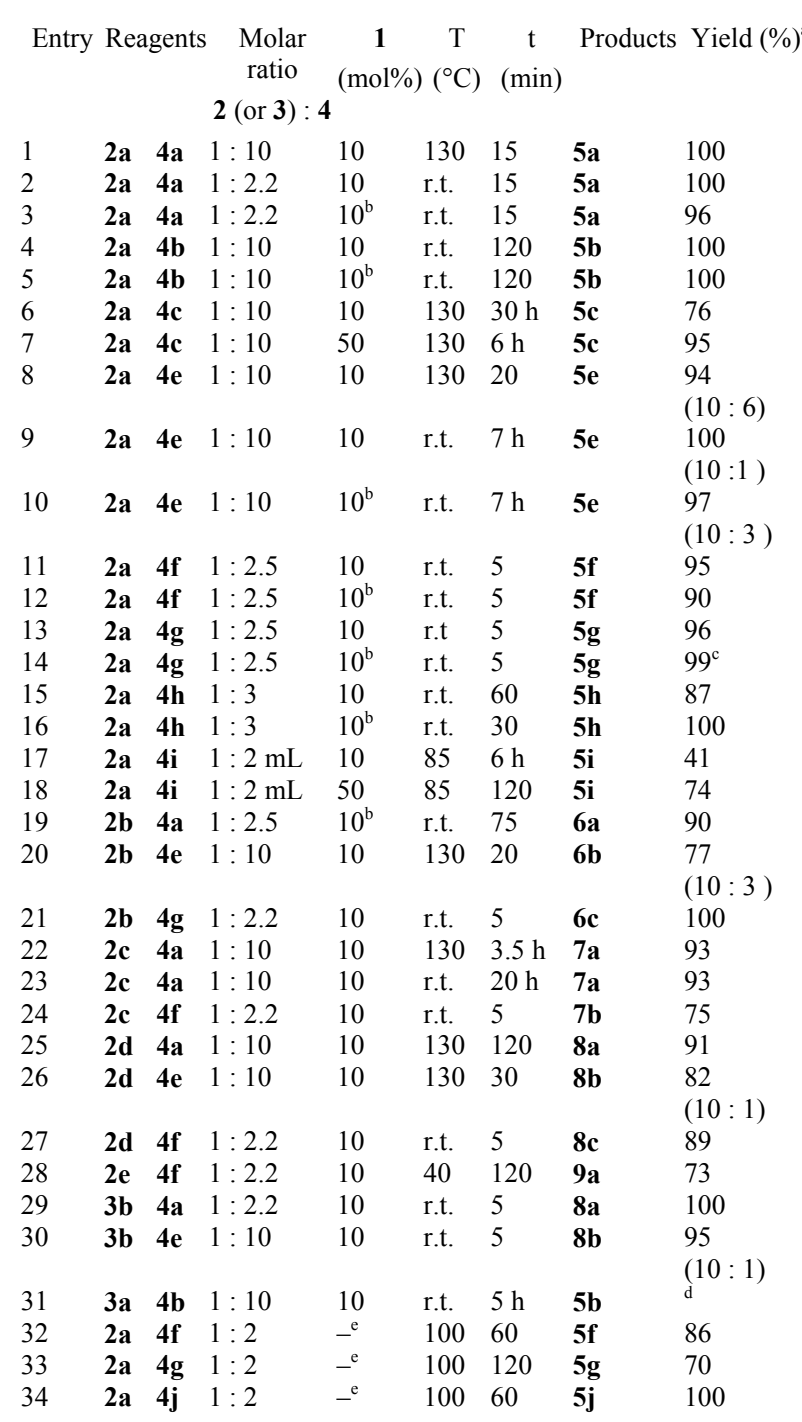

${ }^{a}$ Yields refer to pure isolated products. In parentheses $p, p$ and $o, p$ isomer ratio is reported (calculated by ${ }^{1} \mathrm{H}$ NMR spectra). ${ }^{\mathrm{b}}$ Silica supported OBS. ${ }^{\mathrm{c}}$ The catalyst was recycled for 5 subsequent runs. ${ }^{\mathrm{d}}$ The reaction was incomplete. ${ }^{\mathrm{e}}$ The reaction was carried out in the absence of catalyst.
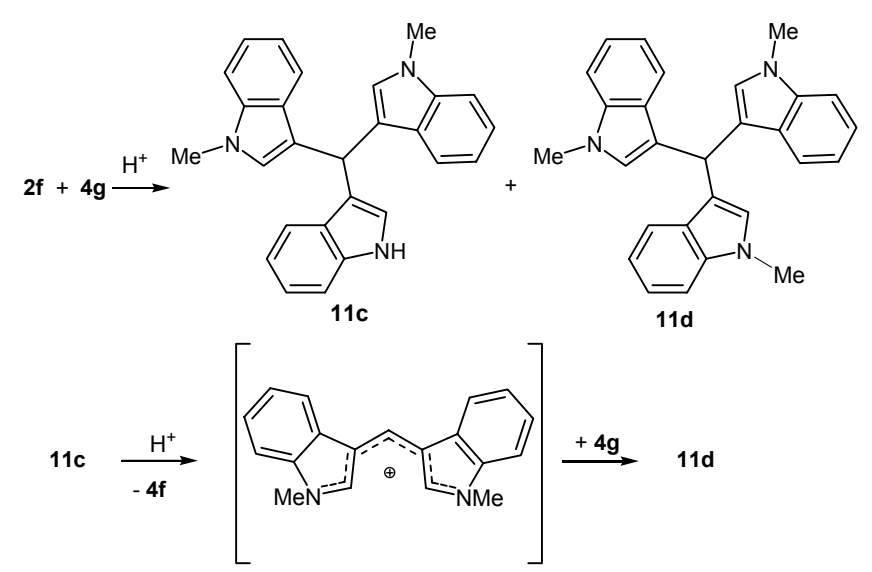

Scheme 4 Proposed mechanism for 11d formation in 11c synthesis. 


\begin{tabular}{|c|c|c|c|c|c|}
\hline Entry & Reagents & $1(\mathrm{~mol} \%)$ & $\mathrm{t}(\min )$ & Products & Yields $(\%)^{b}$ \\
\hline 1 & $4 f$ & 10 & 5 & 11a & 92 \\
\hline 2 & $2 f$ & 10 & 5 & $11 b$ & 72 \\
\hline 3 & $4 \mathrm{~g}$ & 2 & $5 \mathrm{~h}$ & 11c & $90^{c}$ \\
\hline
\end{tabular}

\section{Conclusions}

In conclusion, a new simple and efficient triaryl and trisindolylmethane synthesis has been reported. The advantages of the method are mild solvent-free reaction conditions, in most cases nearly stoichiometric reagent ratios, catalytic amounts of the readily available and easily-handled Brønsted acid catalyst. In our conditions, every effort to stop the reaction at the first step was unsuccessful and the intermediate diarylmethanol was not isolated nor detected. Furthermore, the recoverability and recyclability of the catalyst, both in homogeneous and heterogeneous conditions, are noteworthy.

\section{Experimental}

\section{General Experimental}

All the reactions were run in vials using analytical grade reagents, and were monitored by TLC, GC, GC-MS and NMR spectrometry. GC-MS spectra were recorded with an AT5973N mass selective detector connected to an AT6890N GC cross-linked methyl silicone capillary column. ${ }^{1} \mathrm{H}$ NMR and ${ }^{13} \mathrm{C}$ NMR spectra were recorded in $\mathrm{CDCl}_{3}$ with a Bruker Avance 200 spectrometer at $200 \mathrm{MHz}$ and $50 \mathrm{MHz}$, respectively; chemical shifts are given in ppm relative to $\mathrm{CDCl}_{3}$. TLC were performed on Fluka silica gel TLCPET foils GF 254, 2-25 $\mu \mathrm{m}$, layer thickness 0.2 mm, medium pore diameter $60 \mathrm{~A}^{\circ}$. Plates were visualized using UV light $(254 \mathrm{~nm})$. Column chromatography was carried out on $\mathrm{SiO}_{2}$ (pore size $70 \AA$, 70-230 mesh). Petroleum ether refers to the fraction boiling in the range $40-60{ }^{\circ} \mathrm{C}$ and is abbreviated as PE. Commercially available reagents and solvents were purchased from Aldrich and were used without purification or distillation prior to use; Dowex 50X8 ion-exchange resin was purchased from Fluka. $o$-Benzenedisulfonimide (1) was prepared as described in literature. ${ }^{33}$ Details for the reactions and yields for the pure (GC, GC-MS, TLC, ${ }^{1} \mathrm{H}$ NMR) isolated products are listed in Table 2, 4 and 5. Structure and purity of all the products were confirmed by comparison of their physical and spectral data (IR, MS, ${ }^{1} \mathrm{H}$ NMR and ${ }^{13} \mathrm{C}$ NMR) with those reported in literature. By the work-up of the reaction mixtures, $o$-benzenedisulfonimide could be recovered, purified by elution on Dowex ion-exchange resin and recycled in other reactions. When OBS was used adsorbed onto $\mathrm{SiO}_{2}$, at the end of the reaction, the solid mixture was extracted with small portions of $\mathrm{CH}_{2} \mathrm{Cl}_{2}(6 \times 3 \mathrm{~mL})$ under stirring; the heterogeneous catalyst was then directly recycled after drying under vacuum.

General procedure for triarylmethane $5 \mathbf{a}-\mathbf{i}, 6 \mathbf{a}-\mathbf{c}, 7 \mathbf{a}-\mathbf{b}, 8 \mathrm{a}-\mathbf{c}$ and $9 \mathrm{a}$ synthesis.

A mixture of aldehyde 2 (1.0 mmol), aromatic compound $\mathbf{4}$ (mmol as in Table 4) and $o$-benzenedisulfonimide (1, 10 mol\%, $0.022 \mathrm{~g}$ ) was stirred at r.t. (or under heating, as in Table 4) in a vial until TLC analyses showed almost complete conversion of 2. The reaction mixture was then treated with $\mathrm{CH}_{2} \mathrm{Cl}_{2}-\mathrm{H}_{2} \mathrm{O}(1: 1,20 \mathrm{~mL})$. The aqueous phase was extracted with $\mathrm{CH}_{2} \mathrm{Cl}_{2}(2 \times 20 \mathrm{~mL})$. The organic extracts were dried with $\mathrm{Na}_{2} \mathrm{SO}_{4}$ and concentrated under reduced pressure. The crude residue was purified by column chromatography on a short column of silica gel.

\section{Representative experimental data:}

\section{bis(2,4,5-Trimethoxyphenyl)(4-nitrophenyl)methane (5a). ${ }^{20}$}

Chromatographic eluent: PE-AcOEt (6:4); yellow solid (0.47 g, quantitative yield); mp $125-126{ }^{\circ} \mathrm{C}\left(\mathrm{EtOH}^{2}\left[\mathrm{lit}^{20} 123-\right.\right.$ $\left.124{ }^{\circ} \mathrm{C}\right] ;{ }^{1} \mathrm{H}$ NMR $\left(200 \mathrm{MHz}, \mathrm{CDCl}_{3}\right): \delta=3.58(\mathrm{~s}, 6 \mathrm{H}), 3.61(\mathrm{~s}, 6 \mathrm{H}), 3.83(\mathrm{~s}, 6 \mathrm{H}), 6.04(\mathrm{~s}, 1 \mathrm{H}), 6.32(\mathrm{~s}, 2 \mathrm{H}), 6.49(\mathrm{~s}$, $2 \mathrm{H}), 7.13(\mathrm{~d}, J=9.0 \mathrm{~Hz}, 2 \mathrm{H}), 8.03(\mathrm{~d}, J=8.8 \mathrm{~Hz}, 2 \mathrm{H}) ;{ }^{13} \mathrm{C} \mathrm{NMR}\left(50 \mathrm{MHz}, \mathrm{CDCl}_{3}\right): \delta=42.8,55.9(2 \mathrm{C}), 56.4(2 \mathrm{C}), 56.5$ (2C), 97.8 (2C), 114.2 (2C), 122.1 (2C), 123.0 (2C), 129.4 (2C), 142.6 (2C), 145.9, 148.4 (2C), 151.3 (2C), 152.7; MS (EI) $m / z:(\%) 469\left[\mathrm{M}^{+}\right](100), 438(40), 181(25), 151(25)$.

\section{bis(4-Methoxyphenyl)(4-nitrophenyl)methane (5d) and isomer. ${ }^{20}$}

Chromatographic eluent: PE-AcOEt (7:3); light yellow oil (0.32 g, 91\% yield). Mixture of isomers ( $p, p$ and $o, p$, the former always prevalent) not completely separable. ${ }^{1} \mathrm{H}$ NMR $\left(200 \mathrm{MHz}, \mathrm{CDCl}_{3}\right): \delta=3.66(\mathrm{~s}, 3 \mathrm{H})(o, p), 3.74(\mathrm{~s}, 3 \mathrm{H})$ $(p, p), 5.49(\mathrm{~s}, 1 \mathrm{H})(p, p), 5.87(\mathrm{~s}, 1 \mathrm{H})(o, p), 6.80(\mathrm{~d}, J=8.8 \mathrm{~Hz}, 4 \mathrm{H}), 6.95(\mathrm{~d}, J=8.8 \mathrm{~Hz}, 4 \mathrm{H}), 7.22(\mathrm{~d}, J=8.6 \mathrm{~Hz}, 2 \mathrm{H})$, 8.07 (d, $J=8.8 \mathrm{~Hz}, 2 \mathrm{H}$ ); MS (EI) $m / z(\%): 349\left[\mathrm{M}^{+}\right](100), 318$ (65), 227 (100) (p,p isomer); 349 [M $\left.{ }^{+}\right](100), 319$ (40), 227 (55), 121 (55) (o,p isomer).

\section{General procedure for triarylmethane 5 f,g,j synthesis in the absence of catalyst:}


A mixture of aldehyde $2 \mathrm{a}(1.0 \mathrm{mmol})$ and aromatic compound $4(2 \mathrm{mmol})$ was stirred under heating at $100{ }^{\circ} \mathrm{C}$ in a vial until TLC analyses showed almost complete conversion of starting reagents. The reaction mixture was then treated with $\mathrm{CH}_{2} \mathrm{Cl}_{2}-\mathrm{H}_{2} \mathrm{O}(1: 1,20 \mathrm{~mL})$. The aqueous phase was extracted with $\mathrm{CH}_{2} \mathrm{Cl}_{2}(2 \times 20 \mathrm{~mL})$. The organic extracts were dried with $\mathrm{Na}_{2} \mathrm{SO}_{4}$ and concentrated under reduced pressure. The crude residue was purified by column chromatography on a short column of silica gel. Details are reported in Table 4.

\section{Representative experimental data:}

\section{bis(2-Methyl-3-indolyl)(4-nitrophenyl)methane (5j). ${ }^{34}$}

Chromatographic eluent: PE-AcOEt (4:6); yellow solid (0.38 g, quantitative yield); dp 239-242 ${ }^{\circ} \mathrm{C}\left(\mathrm{CH}_{2} \mathrm{Cl}_{2}-\mathrm{PE}\right.$ [lit. ${ }^{40}$ 241-243 $\left.{ }^{\circ} \mathrm{C}\right] ;{ }^{1} \mathrm{H}$ NMR $\left(200 \mathrm{MHz}, \mathrm{CD}_{3} \mathrm{CN}\right): \delta=2.05(\mathrm{~s}, 6 \mathrm{H}), 6.06(\mathrm{~s}, 1 \mathrm{H}), 6.69-6.81(\mathrm{~m}, 4 \mathrm{H}), 6.88-6.96(\mathrm{~m}, 2 \mathrm{H}), 7.23$ $(\mathrm{d}, J=8.0 \mathrm{~Hz}, 2 \mathrm{H}), 7.37(\mathrm{~d}, J=9.0 \mathrm{~Hz}, 2 \mathrm{H}), 8.05(\mathrm{~d}, J=9.0 \mathrm{~Hz}, 2 \mathrm{H}), 9.01(\mathrm{br} \mathrm{s}, 2 \mathrm{H}) ;{ }^{13} \mathrm{C} \mathrm{NMR}\left(50 \mathrm{MHz}, \mathrm{CD}{ }_{3} \mathrm{CN}\right): \delta=$ 11.1 (2C), 38.9, 110.3 (2C), 111.2 (2C), 118.4 (2C), 118.5 (2C), $120.2(2 \mathrm{C}), 123.0(2 \mathrm{C}), 128.0(2 \mathrm{C}), 129.6(2 \mathrm{C}), 132.6$ (2C), $135.2(2 \mathrm{C}), 146.2,152.5$.

\section{General procedure for trisindolylmethane $11 \mathrm{a}-\mathrm{c}$ synthesis:}

A mixture of 3-formylindole $\mathbf{2 f}(0.15 \mathrm{~g}, 1.0 \mathrm{mmol})$, aromatic compound 4 (2.2 mmol) and $o$-benzenedisulfonimide (1, mol\% as in Table 5) in EtOH ( $2 \mathrm{~mL})$ was stirred at r.t. in a vial until TLC analyses showed almost complete conversion of $2 \mathrm{f}$. The reaction mixture was then treated with $\mathrm{CH}_{2} \mathrm{Cl}_{2}-\mathrm{H}_{2} \mathrm{O}(1: 1,20 \mathrm{~mL})$. The aqueous phase was extracted with $\mathrm{CH}_{2} \mathrm{Cl}_{2}(2 \times 20 \mathrm{~mL})$. The organic extracts were dried with $\mathrm{Na}_{2} \mathrm{SO}_{4}$ and concentrated under reduced pressure. The crude residue was purified by column chromatography on a short column of silica gel; eluent: PE-AcOEt (6:4).

\section{Representative experimental data: \\ Tris(3-indolyl)methane (11a). ${ }^{32 a}$}

Chromatographic eluent: PE-AcOEt (4:6); light orange solid (0.33 g, 92\% yield); dp 229-234 ${ }^{\circ} \mathrm{C}$ (Acetone-PE) [lit. ${ }^{32 \mathrm{a}}$ $\left.240{ }^{\circ} \mathrm{C}\right] ;{ }^{1} \mathrm{H}$ NMR $\left(200 \mathrm{MHz}, \mathrm{CD}_{3} \mathrm{CN}\right): \delta=6.08(\mathrm{~m}, 1 \mathrm{H}), 6.80-6.90(\mathrm{~m}, 6 \mathrm{H}), 6.95-7.08(\mathrm{~m}, 3 \mathrm{H}), 7.27-7.40(\mathrm{~m}, 6 \mathrm{H})$, 9.07 (br s, 3H); ${ }^{13} \mathrm{C}$ NMR $\left(50 \mathrm{MHz}, \mathrm{CD}_{3} \mathrm{CN}\right): \delta=31.0,111.1$ (3C), $118.3(3 \mathrm{C}), 118.7(3 \mathrm{C}), 119.2(3 \mathrm{C}), 121.1(3 \mathrm{C})$, $123.0(3 \mathrm{C}), 126.8(3 \mathrm{C}), 136.7(3 \mathrm{C})$.

\section{Acknowledgements}

This work was supported by Italian MIUR and by Università degli Studi di Torino.

\section{Notes and references}

${ }^{a}$ Dipartimento di Chimica Generale e Chimica Organica dell'Università, Università di Torino, Via P. Giuria 7, 10125 Torino, Italy E-mail: margherita.barbero@unito.it

$\dagger$ Electronic Supplementary Information (ESI) available: General procedures, ${ }^{1} \mathrm{H},{ }^{13} \mathrm{C}$ NMR and MS spectra of products 5a-j, 6a-c, 7a-b, 8a-c, 9a, 11a-d. See DOI: 10.1039/b000000x/

1 (a) V. Nair, S. Thomas, S. C. Mathew and K. G. Abhilash, Tetrahedron, 2006, 62, 6731; (b) Shchepinov, M. S.; Korshun, V. A. Chem. Soc. Rev. 2003, 32, 170.

2 (a) P. J. Kocienski, in Protective Groups, 3rd ed., Georg Thieme, Stuttgart, 2003; (b) T. W. Greene and P. G. M. Wuts, in Protective Groups in Organic Synthesis, 3rd ed., Wiley, New York, 1999.

3 M. Irie, J. Am. Chem. Soc., 1983, 105, 2078.

4 R. Muthyala, A. R. Katritzky and X. Lan, Dyes Pigm., 1994, 25, 303.

5 (a) L. Sanguinet, R. I. Twieg, G. Wiggers, G. Mao, K. D. Singer and R. G. Petschek, Tetrahedron Lett., 2005, 46, 5121; (b) S. K. D. Shagufta and G. Panda, Tetrahedron Lett., 2005, 46, 3097.

6 M. Nibu, K. Yokomizo, M. Uyeda and K. Sumoto, Chem. Pharm. Bull., 2005, 53, 1171.

7 H. Griepntrog, Ber. Dtsch. Chem. Ges. 1886, 19, 1876.

8 V. Nair, K. G. Abhilash and N. Vidya, Org. Lett., 2005, 7, 5857.

9 S. Genovese, F. Epifano, C. Pelucchini and M. Curini, Eur. J. Org. Chem., 2009, 1132.

10 S. Ch. Gagieva, T. A. Sukhova, D. V. Savinov, V. A. Tuskaev, K. A. Lyssenko, N. M. Bravaya, Yu. N. Belokon and B. M. Bulychev, Russ. Chem. Bull. Int. Ed., 2006, 55, 1794.

11 S. Chandrasekhar; S. Khatun; G. Rajesh and Ch. R. Reddy, Tetrahedron Lett., 2009, 50, 6693.

12 J. Jaratjaroonphong, S. Sathalalai, P. Techasauvapak and V. Reutrakul, Tetrahedron Lett., 2009, 50, 6012.

13 S. Podder, J. Choudhury, U. K. Roy and S. Roy, J. Org. Chem., 2007, 72, 3100.

14 G. A. Olah, G. K. S. Prakash, J. Sommer and A. Molnàr, in Superacid Chemistry, Wiley, New York, 2009.

15 G. K. S. Prakash, C. Panja, A. Shakhmin, E. Shah, T. Mathew and G. A. Olah, J. Org. Chem., 2009, 74, 8659.

16 T. Ohishi, T. Kojima, T. Matsuoka, M. Shiro and H. Kotsuki, Tetrahedron Lett., 2001, 42, 2493.

17 N. Mibu, K. Yokomizo,T. Miyata and K. Sumoto, J. Heterocycl. Chem., 2010, 47, 1434 and references therein.

18 B. A. Roberts, G. W. V. Cave, C. L. Raston and J. L. Scott, Green Chem., 2001, 3, 280.

19 R. Goossens, M. Smet and W. Dehaen, Tetrahedron Lett., 2002, 43, 6605.

20 Y. Leng, F. Chen, L. Zuo and W. Duan, Tetrahedron Lett., 2010, 51, 2370.

21 L.-T. An, F.-Q. Ding and J.-P. Zou, Dyes Pigm., 2008, 77, 478.

22 M. A. Zolfigol, P. Salehi, M. Shiri, A. Sayadi, A. Abdoli, H. Keypur, M. Rezaeivala, K. Niknam and E. Kolvari, Mol. Divers., 2008, 12, 203.

23 S. G. K. Prakash, G. Fogassy and G. A. Olah, Catal. Lett., 2010, 138, 155.

24 M. Kodamari, M. Nagamatsu, M. Akaike and T. Aoyama, Tetrahedron Lett., 2008, 49, 2537.

25 Z. Li, Z. Duan, J. Kang, H. Wang, L. Yu, and Y. Wu, Tetrahedron, 2008, 64, 1924.

26 M. Shiri, M. A. Zolfigol, H. G. Kruger and Z. Tanbakouchian, Chem. Rev., 2010, 110, 2250 and references therein. 
27 F. He, P. Li, Y. Gu and G. Li, Green Chem., 2009, 11, 1767.

28 (a) M. Barbero, S. Bazzi, S. Cadamuro, S. Dughera, C. Magistris, A. Smarra and P. Venturello, Org. Biomol. Chem., 2011, 9, 2192 and references therein. (b) M. Barbero, S. Bazzi, S. Cadamuro and S. Dughera, Curr. Org. Chem., $2011, \mathbf{1 5}, 576$.

29 In literature many examples of Brønsted acids supported onto silica are reported; among them worthy of mention are silica-supported phosphomolybdic acid, perchloric acid, polyphosphoric acid, sol-gel heteropolyoxotungstate, silicotungstic acid, phosphotungstic acid, fluoroboric acid, $\mathrm{NaHSO}_{4}$ and $\mathrm{LiHSO}_{4}$.

30 N. Mibu, K. Yokomizo, M. Uyeda and K. Sumoto, Chem. Pharm. Bull., 2003, 51, 1325.

31 J. M. Oclarit, S. Ohta, K. Kamimura, Y. Yamaoka, T. Shimitzu and S. Ikegami, Nat. Prod. Lett., 1994, 4, 309.

32 For examples see: (a) A. Hazra, P. Paira, K. B. Sahu, S. Banerjee and N. B. Mondal, Catal. Commun., 2008,9, 1681 ; (b) S. Naskar, A. Hazra, P. Paira, K. B Sahu, S. Banerjee and N. B. Mondal, J. Chem. Res., 2008, 568; (c) M. Chakrabarty and S. Sarkar, Tetrahedron Lett., 2002, 43, 1351; (d) H. Koshima and W. Matsusaka, J. Heterocycl. Chem., 2002, 39, 1089; (e) J. Bergman, J. Heterocycl. Chem., 1985, 22, 341.

33 M. Barbero, M. Crisma, I. Degani, R. Fochi and P. Perracino, Synthesis, 1998, 1171.

34 A. Hasaninejad, A. Zare, H. Sharghi, K. Niknam and M. Shekouhy, Arkivoc, 2007, (xiv), 39. 